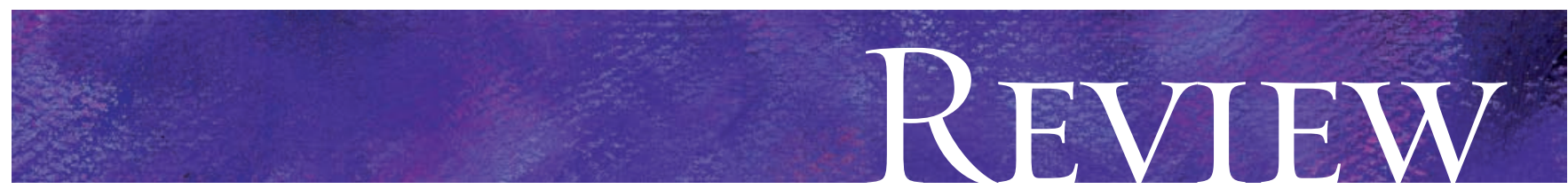

\title{
Sudden infant death syndrome
}

\author{
Carl E. Hunt, Fern R. Hauck
}

\section{ABSTRACT}

Sudden infant death syndrome (SIDS) continues to be the most common cause of postneonatal infant death. SIDS is a complex, multifactorial disorder, the cause of which is still not fully understood. However, much is known now about environmental risk factors, some of which are modifiable. These include maternal and antenatal risk factors such as smoking during pregnancy, as well as infant-related risk factors such as non-supine sleeping position and soft bedding. Emerging evidence also substantiates an expanding number of genetic risk factors. Interactions between environmental and genetic risk factors may be of critical importance in determining an infant's actual risk of SIDS. Although no practical way exists to identify which infants will die of SIDS, nor is there a safe and proven prevention strategy even if identification were feasible, reducing exposure to modifiable risk factors has helped to lower the incidence of SIDS. Current challenges include wider dissemination of guidelines to all people who care for infants, dissemination of guidelines in culturally appropriate ways, and surveillance of SIDS trends and other outcomes associated with implementation of these guidelines.

CMAJ 2006;174(13):186I-9

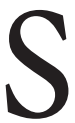
udden infant death syndrome (SIDS) is defined as the sudden death of an infant under I year old that is unexpected by history and unexplained after a thorough postmortem examination, including a complete autopsy, investigation of the scene of death and review of the medical history. ${ }^{1}$ Despite declines in SIDS rates of more than $50 \%$ in Canada, the United States and many other countries, SIDS continues to be the leading cause of postneonatal infant death, accounting for about $25 \%$ of all deaths between I month and I year of age. ${ }^{2-4}$ The declines in rates are attributed in large part to educational campaigns advocating that infants be placed on their back to sleep, that an overall safe sleeping environment be provided and that other potential risk-reduction measures be taken. The SIDS rates in Canada and the United States were 0.3 and 0.6 per Iooo live births respectively in 2002, compared with rates of 0.8 and I.3 per Iooo live births respectively in I990 (Canada: Statistics Canada and Canadian WHO Statistical Information Services; Aurore Coté: personal communication, 2005)..$^{2,3}$ There is evidence in some countries, however, that this remarkable progress is reaching a plateau. Changes in the classification of sudden unexpected deaths in infants by medical examiners, coroners and other certifiers from SIDS to the categories of asphyxia and "unknown" may be falsely reducing SIDS rates while the overall rate of death from unexpected deaths in infants remains the same. ${ }^{4,5}$ In order to reduce SIDS rates further, it may be necessary to develop more robust campaigns or other intervention strategies that focus on all of the modifiable risk factors.

Researchers continue to investigate possible causes of SIDS and the factors associated with an increased or decreased risk of occurrence. More recently, the genetic basis of SIDS has been an emerging area of research. In this review, we summarize the pathophysiology, epidemiology and genetic risk factors as well as the interactions between genetic and environmental risk factors, with particular emphasis on newer findings. In addition, we include the new SIDS policy statement from the American Academy of Pediatrics.

\section{Pathophysiology}

There are no routine autopsy findings pathognomonic of SIDS and no findings required for its diagnosis. There are, however, some common observations. ${ }^{6}$ Petechial hemorrhages occur in $68 \%-95 \%$ of cases and are more extensive than in explained causes of infant death. Pulmonary congestion is present in $89 \%$ of SIDS cases $(p<0.00$ I compared with non-SIDS deaths), and pulmonary edema in $63 \%(p<0.01)$.

In autopsies performed according to a research protocol, infants who died of SIDS were found to have several identifiable changes in the lungs and other organs and in brainstem structure and function. ${ }^{6,7}$ Nearly two-thirds of them had structural evidence (tissue markers) of pre-existing, chronic low-grade asphyxia, and other studies identified biochemical markers of asphyxia, including vascular endothelial growth factor (VEGF) in cerebrospinal fluid (CSF). ${ }^{8}$ The mean VEGF concentration in CSF was 308 (standard deviation [SD] 299) $\mathrm{pg} / \mathrm{dL}$ in SIDS cases compared with 85 (SD 83) pg/dL in nonSIDS-related infant deaths. SIDS infants have been found to have structural and neurotransmitter alterations in the brainstem, consistent with abnormalities in autonomic regulation. These brainstem findings include persistent increases in dendritic spines (indicating neuronal maturational delay) and delayed maturation of synapses in medullary respiratory centres, decreased tyrosine hydroxylase immunoreactivity in catecholaminergic neurons, and decreases in serotonin $(5-\mathrm{HT})$ IA and $2 \mathrm{~A}_{-}$receptor immunoreactivity. ${ }^{6,7}$ 
Up to $60 \%$ of SIDS cases have been found to show histopathological evidence of varying degrees of hypoplasia of the arcuate nucleus, an integrative site for vital autonomic functions, and neurotransmitter studies have identified receptor abnormalities in some SIDS cases that involve several receptor types relevant to autonomic control. ${ }^{9}$ These deficits include significant decreases in binding to kainate, muscarinic cholinergic and 5 -HT receptors.

\section{Risk factors}

A number of factors, both modifiable and not, have been found to have significant associations with SIDS (Box I). It is possible that the case-control design, used frequently in studying risk factors for SIDS, introduces unmeasured biases through both selection and participation of cases and controls. ${ }^{10}$ However, studies using complete cohort and case series data have confirmed findings from case-control studies. ${ }^{11-14}$ In addition, multiple logistic regression analysis of data from case-control studies does control for potential confounders to a substantial extent, albeit perhaps not always completely. Although we can never be fully sure that all possible confounders are considered in these analyses, the general consistency of findings across studies for many of the risk factors described herein strengthens their overall validity.

\section{Sociodemographic factors}

Although SIDS affects infants from all social strata, lower socioeconomic status, younger maternal age, lower maternal education level and single marital status are consistently as-

Box 1: Environmental factors associated with an increased risk of sudden infant death syndrome (SIDS)*
Maternal and antenatal

risk factors

- Smoking

- Alcohol use (especially periconceptionally and in first trimester)

- Illegal drug use (especially opiates)

- Inadequate prenatal care

- Low socioeconomic status

- Low age

- Low level of education

- Single marital status

- Increased parity

- Short interval between pregnancies

- Intrauterine hypoxia

- Fetal growth retardation

\section{Infant risk factors}

- Age (peak 2-4 mo, but peak may be decreasing)

- Male sex

- Race/ethnic background (e.g., black, Native Indian, other indigenous group)

- No pacifier (“dummy”) used at bed time

- Prematurity

- Prone or side sleeping position

- Recent febrile illness

- Exposure to tobacco smoke

- Soft sleeping surface, soft bedding

- Thermal stress/overheating

- Face covered by bedding

- Sharing bed with parents or siblings

- Sleeping in own room rather than in parents' room

- Colder season, no central heating
"Adapted from Hunt and Hauck. ${ }^{7}$ sociated with an increased risk of SIDS. In the United States, who are black, American Indian and Alaskan Native the among indignous peoples than in other groups have been reported in other countries. ${ }^{2}$ Some of this disparity may be related to the higher concentration of poverty and other adverse environmental factors found in the communities with higher ence. Despite declines in SIDS across all social and racial fowing educational campaigns, recent trends indiisparities..$^{11,12,15}$

Infants are at greatest risk of SIDS at 2-4 months of age, with most SIDS-related deaths having occurred by 6 months. This characteristic age distribution has decreased in some ntries as the SIDS incidence has declined, with occurrence eaths at earlier ages and flattening of the peak inciSimilarly, the commonly found winter seasona of SIDS has declined or disappeared in some osition as the prevalence of infants sleeping in the prone interaction between sleeping position and factors more common during colder months (e.g., overheating and infecion). ${ }^{18,19}$ Infant boys are $30 \%-50 \%$ more likely than girls to Pregnancy-related factors

Several pregnancy-related factors are associated with an increased risk of SIDS, which suggests a suboptimal in utero environment. ${ }^{2}$ Studies have shown that mothers of SIDS infants generally receive less prenatal care and initiate care later in pregnancy than do mothers of living control infants. ${ }^{21,23}$ Other pregnancy-related risk factors include low birth weight, preterm birth, intrauterine growth retardation and shorter intervals between pregnancies. ${ }^{21,22,24}$ SIDS infants are often the second or higher-order birth child. This effect may be related to social strain in the care environment or possibly to increased risk of infection from siblings. ${ }^{11}$

\section{Maternal substance use}

There is a major association between intrauterine exposure to cigarette smoking and risk of SIDS. In studies comparing SIDS rates before and after riskreduction campaigns, infants of mothers who smoked were about 3 times more likely than those whose mothers did not smoke to die of SIDS before implementation of the campaigns and 5 times more likely after the campaigns. ${ }^{25}$ Most studies have shown that the risk of death is pro- 
gressively greater as daily cigarette use increases, but the accuracy of self-reported cigarette use data is uncertain. ${ }^{22,24,26}$ There may be a small independent effect of paternal smoking. ${ }^{25}$ It is difficult to assess the independent effect of postnatal exposure to environmental tobacco smoke, because parental smoking behaviours during and after pregnancy are highly correlated. ${ }^{25}$ An independent effect of postnatal exposure to tobacco smoke has been found in a small number of studies as well as a dose response for the number of household smokers, people smoking in the same room as the infant, cigarettes smoked and time the infant was exposed..$^{27-31}$ These data suggest that keeping the infant free of environmental tobacco smoke may further reduce an infant's risk of SIDS.

The evidence linking prenatal illegal drug use and SIDS is conflicting. Overall, the studies do link maternal prenatal drug use, especially opiates, with an increased risk of SIDS ranging from 2- to 15 -fold. ${ }^{2,31-35}$ In general, studies have not found an association between SIDS and maternal alcohol use prenatally or postnatally. In one study involving Northern Plains Indians, however, periconceptional alcohol use and binge drinking in the first trimester were associated with a 6-fold and an 8-fold increased risk of SIDS, respectively. ${ }^{36}$ In a Dutch study, maternal alcohol consumption in the 24 hours before the infant died was associated with a $2-8$-fold increased risk. ${ }^{37}$ Siblings of infants with fetal alcohol syndrome have been reported to have a Io-fold increased risk of SIDS compared with controls. ${ }^{38}$

\section{Infant sleep practices and environment}

The prone sleeping position has consistently been shown to increase an infant's risk of SIDS..$^{39}$ As rates of prone sleeping have decreased in the general population, the odds ratios for SIDS among infants still sleeping prone have increased. For example, in Norway the odds ratio for SIDS among infants sleeping prone was 2.0 before an educational campaign and II.o after the campaign.$^{40}$ Infants at highest risk of SIDS may be those who are usually placed in another sleeping position but were placed on their stomachs for last sleep ("unaccustomed prone") or were found in the prone position ("secondary prone"). ${ }^{39}$ The unaccustomed prone position is more likely to occur in daycare or other settings outside the home and highlights the need for all infant caretakers to be educated about appropriate sleep positioning. Initial recommendations in SIDS risk-reduction campaigns considered placing an infant on his or her side to sleep to be nearly equivalent to the supine position in reducing the risk of SIDS, but subsequent studies have indicated that infants who sleep on their side are twice as likely to die of SIDS as infants sleeping supine. ${ }^{41}$ Thus, current recommendations call for placing all infants on their back for sleep except those few with specific medical conditions, for which a different position may be justified. ${ }^{39}$ Some newborn nursery staff still place infants on their side, which models inappropriate infant care practice to parents. Many parents and health care providers were initially concerned that supine sleeping would be associated with an increased risk of adverse conse- quences (e.g., difficulty sleeping, vomiting or aspiration). However, evidence suggests that the risk of regurgitation and choking is highest among infants who sleep in the prone position. ${ }^{42}$ Infants sleeping on their backs have not been shown to have more episodes of cyanosis or apnea than infants sleeping in other positions, and reports of apparent life-threatening events decreased in Scandinavia after increased use of the supine position..$^{43}$ A US cohort study showed that infants sleeping on their back or side were not more likely than prone sleepers to have clinical symptoms or reasons for outpatient visits, and some symptoms and visits were actually less common among the supine sleepers. ${ }^{44}$

Soft mattresses, older mattresses and soft, fluffy bedding such as comforters, pillows, sheepskins and polystyrene-bean pillows have been associated with a 2-3-fold increased risk of SIDS. ${ }^{2,20,45}$ Combinations of risk factors result in even higher risk; for example, prone sleeping in soft bedding has been associated with a 20 -fold increased risk of SIDS..$^{46}$ Loose bedding, including heavy comforters, covering the head and face has also been associated with an increased risk. ${ }^{40,47}$ Overheating has been associated with increased risk of SIDS based on indicators such as increased room temperature, high body temperature, sweating, and excessive clothing or bedding. ${ }^{2}$ Some studies have identified an interaction between overheating and prone sleeping, with overheating increasing the risk of SIDS 6-Io-fold only among infants sleeping in the prone position. ${ }^{48,49}$ High external environmental temperatures, however, have not been associated with increased SIDS incidence in the United States. ${ }^{50}$

Several studies have implicated bed sharing as a risk factor for SIDS. Earlier case-control studies in England and New Zealand showed a $5-9$-fold increased risk associated with bed sharing only among infants of mothers who smoked. ${ }^{51,52}$ More recent studies have found that bed sharing was associated with increased risk of SIDS even if mothers did not smoke or if they breast-feed, particularly among younger infants. ${ }^{22,24,53}$ Bed sharing has been found to be extremely hazardous when other children are in the same bed, when the parent is sleeping with an infant on a couch or other soft or confining sleep surface and when the infant is less than 4 months of age. ${ }^{24,46,51,53,54}$ Risk is also increased with longer duration of bed sharing during the night; returning the infant to his or her own crib was not associated with increased risk. ${ }^{51,54}$ Some authors have hypothesized potentially protective effects among infants who are bed sharing and breast-feeding based on observations from sleep laboratory studies, including improved maternal inspections, more infant arousals and less deep sleep. ${ }^{55,56}$ However, no epidemiologic studies have reported a protective effect from bed sharing, and bed sharing hence should not be encouraged as a method of reducing SIDS risk. There is evidence that sleeping in the parents' room without bed sharing is associated with about a third the risk of SIDS compared with sleeping in a room separate from the parents. ${ }^{24,51,53,57}$ Thus, the safest place for an infant to sleep may be in the parents' bedroom in a separate crib or bassinet. 
Box 2: Genes identified in case-control studies for which the distribution of polymorphisms differed between infants who died of SIDS and control infants*

Cardiac ion channelopathies

- Sodium channel (SCN5A)

- Potassium channel

Promoter region of the serotinin (5-HT) transporter gene (5-HTT)

Autonomic nervous system development

- Paired-like homeobox 2a (Phox2a)

- Rearranged during transfection (RET)

- Endothelin-converting enzyme-1 (ECE1)

- T-cell leukemia homeobox (TLX3)

- Engrailed-1 (EN1)

Infection and inflammation

- Complement C4A and C4B

- Interleukin-10

*Adapted from Hunt. ${ }^{70}$

\section{Infant feeding practices and exposures}

The association between breast-feeding and SIDS is inconclusive, which may reflect the different ways in which breastfeeding is defined and measured..$^{39}$ Most studies demonstrated a protective effect of breast-feeding that was not present after adjusting for confounding factors, which suggests that breast-feeding is a marker for lifestyle or socioeconomic status and not an independent factor. ${ }^{2}$ A few studies showed a reduced risk even after adjustment for potential factors, or they showed a dose response in which longer breastfeeding duration was associated with lower risk. ${ }^{16,22} \mathrm{~A}$ recent analysis from the United States found that breast-feeding is associated with a decreased risk of postneonatal deaths overall but not with a decreased risk of SIDS..$^{58}$ Although the benefits of breast-feeding are many, data are currently inadequate to recommend it as a strategy to reduce the risk of SIDS.

Use of a pacifier has been associated with a significantly lower risk of SIDS in the majority of case-control studies when used for last or reference sleep. A meta-analysis found this reduced risk to be equal to an adjusted summary odds ratio of 0.39 (95\% confidence interval $[\mathrm{CI}] 0.3 \mathrm{I}-0.50) .{ }^{59} \mathrm{~A}$ recent California study found an even lower risk associated with pacifier use during last sleep (adjusted odds ratio 0.08 [95\% CI 0.03-0.2I]), and reduced risk was found in all sociodemographic and risk categories examined, including breast-fed infants. ${ }^{60}$ It is not known whether this reduction results from a direct effect of the pacifier itself or from associated infant or parental behaviours. There is increasing evidence, however, that pacifier use and dislodgement may enhance arousability of infants during sleep or help regulate autonomic control. . $^{61,62}$

Concerns have been expressed about recommending pacifiers as a means of reducing the risk of SIDS for fear of creating adverse consequences, particularly interference with breast-feeding. ${ }^{63-65}$ However, no association between pacifier use and breast-feeding duration has been found in welldesigned randomized controlled trials when the pacifier was introduced after breast-feeding was established. ${ }^{59}$ Small increases in the incidence of otitis media and of respiratory tract and gastrointestinal illness have been reported among pacifier users compared with nonusers..$^{39}$ One study found that the risk of SIDS was increased among habitual pacifier users who did not use it for last sleep compared with those who did use it for last sleep and those who never used a pacifier. ${ }^{54}$ This finding was not found in other studies in multivariate analysis. ${ }^{63,66}$ The finding suggests, however, that for habitual users, pacifiers should be used consistently when placed for sleep. The Netherlands and Germany have recommended pacifier use as a way to potentially reduce the risk of SIDS. ${ }^{67,68}$ The most recent American Academy of Pediatrics guidelines recommend pacifier use once breast-feeding has been established. ${ }^{39}$ The Canadian Paediatric Society recommends that counselling about pacifiers be part of routine anticipatory guidance, but "until further research leads to more conclusive evidence on adverse outcomes," pacifier use should be a matter of parental choice. ${ }^{64,69}$ The Canadian Paediatric Society also recommends that the use of pacifiers not be routinely discouraged, since the current evidence suggests a decreased risk of SIDS associated with their use.

Upper respiratory tract infections have generally not been found to be an independent risk factor for SIDS. These and other minor infections, however, may play a role in the pathogenesis of SIDS. An increased risk of SIDS, for example, has been found to be associated with illness among infants sleeping in the prone position, those heavily wrapped and those whose heads were covered during sleep. ${ }^{2}$

In case-control studies, fewer SIDS infants than control infants were found to have been immunized. ${ }^{39}$ However, among immunized infants, no temporal relation between vaccine administration and death has been identified. Parents should be reassured that immunization does not present a risk for SIDS. ${ }^{39}$

\section{Genetic risk factors}

Sequencing the estimated 25000 genes in the human genome has resulted in fundamental changes in our understanding of the role of specific genes in both health and disease. Genetic studies have now identified multiple ways in which infants who died of SIDS differ from healthy infants and those dying of other causes (Box 2).$^{70,71}$ Long QT syndrome is associated with sodium- and potassium-channel polymorphisms. ${ }^{72}$ Overall, it is estimated that $5 \%-10 \%$ of SIDS cases are associated with a defective cardiac ion channel and hence an increased potential for a lethal arrhythmia.

Several studies have identified polymorphisms in the serotonin transporter $(5-H T T)$ gene in infants who have died of SIDS. ${ }^{70}$ Serotonin $(5-\mathrm{HT})$ is a widespread neurotransmitter that affects a wide array of autonomic functions, including breathing, cardiovascular and circadian regulation. Several polymorphisms have been identified in the promoter region of the 5-HTT gene. Compared with the $S$ allele, the L allele in- 
creases effectiveness of the promoter, resulting in reduced 5HT concentrations at nerve endings. White, black and Japanese infants who died of SIDS were more likely than matched controls to have the $\mathrm{L}$ allele. There is also a negative association between SIDS and the S/S genotype. The L/L genotype has been associated with increased 5 -HT transporters on neuroimaging and postmortem binding studies in SIDS infants. ${ }^{73}$

Genetic studies have identified mutations in SIDS infants pertinent to early embryologic development of the autonomic nervous system. ${ }^{74}$ The 5 genes with identified mutations are listed in Box 2. Genetic differences among SIDS infants have also been reported for the complement $\mathrm{C}_{4}$ gene: in a casecontrol study, SIDS infants who had a mild upper respiratory tract infection before death were more likely than SIDS infants without infection and living control subjects to have deletion of either the $\mathrm{C}_{4} \mathrm{~A}$ or $\mathrm{C}_{4} \mathrm{~B}$ gene. ${ }^{75}$ Partial deletions of the $\mathrm{C}_{4}$ gene in combination with a mild upper respiratory tract infection may thus increase the risk of SIDS. SIDS infants have also been reported to have polymorphisms in the gene promoter region for interleukin-Io (IL-IO), an antiinflammatory cytokine. IL-Io polymorphisms result in decreased IL-Io levels, which could lead to decreases in antibody production or increases in inflammatory cytokine production. ${ }^{76}$

No cost-effective way currently exists to screen for any of these genetic polymorphisms in early infancy. Indeed, except for the cardiac ion channelopathies, no specific clinical abnormality or phenotype has been delineated for the polymorphisms identified in SIDS infants. However, abnormalities one might expect from the identified polymorphisms are consistent with autopsy findings and with the physiologic studies available in young infants later dying of SIDS and in infants at increased risk of SIDS (siblings of prior SIDS infants and infants having had an apparent lifethreatening event). ${ }^{77,78}$ The observed physiologic abnormalities are indicative of deficient brainstem autonomic neuroregulation including respiratory pattern, chemoreceptor sensitivity, control of heart and respiratory rate and variability, and asphyxic arousal responsiveness. A deficit in arousal responsiveness may be a necessary prerequisite for SIDS to occur but may be insufficient to cause SIDS in the absence of other genetic or environmental risk factors. ${ }^{79}$

The ability to shorten the QT interval as the heart rate increases appears to have been impaired in some SIDS infants, which suggests that such infants may be predisposed to ventricular arrhythmia. ${ }^{80}$ This is consistent with observations of cardiac channel gene polymorphisms in other SIDS cases, but there are no antemortem QT-interval data available for SIDS infants with postmortem genetic data. Infants who later died of SIDS were found to have higher heart rates and diminished heart rate variability in all sleep and waking states. ${ }^{77}$ Some infants who later died of SIDS had deficient autonomic heart rate responses to obstructive apnea, which may have led to reduced electrical stability of the heart in response to external or endogenous stress factors. ${ }^{78}$

\section{Interactions between genetic and environmental risk factors}

The actual risk of SIDS in individual infants is determined by complex interactions between genetic and environmental risk factors (Fig. I). There appears, for example, to be an interaction between prone sleeping position and impaired ventilatory and arousal responsiveness. ${ }^{77}$ Face-down or nearly facedown sleeping does occasionally occur in prone-sleeping infants and can result in episodes of airway obstruction, but healthy infants will arouse before such episodes become lifethreatening. ${ }^{81}$ However, infants with insufficient arousal responsiveness to asphyxia would be at risk of sudden death. ${ }^{78}$ There may also be interactions between modifiable risk factors such as use of soft bedding, prone sleeping position and thermal stress, and links between genetic risk factors such as

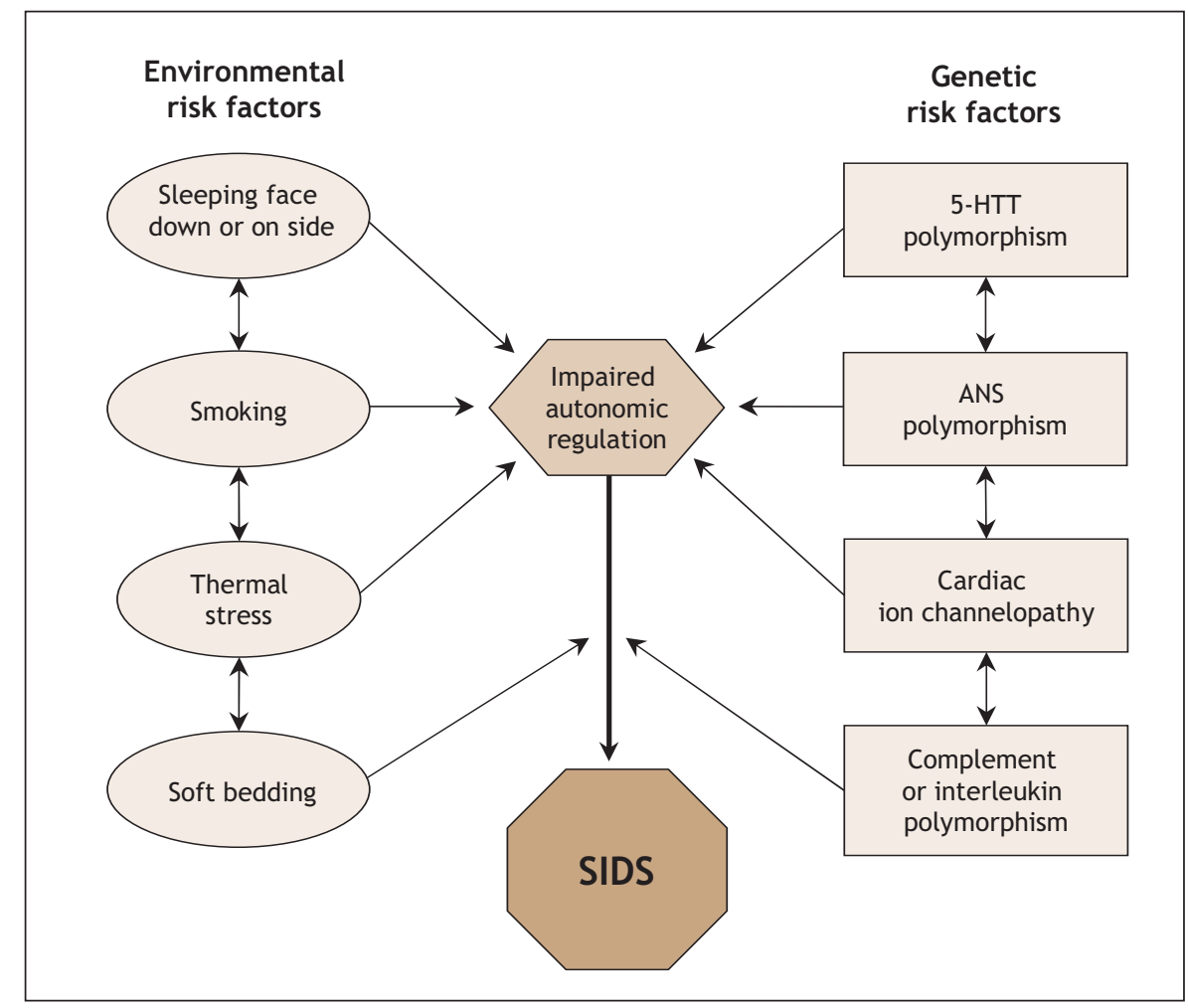

Fig. 1: Schematic summary of potential interactions between environmental and genetic risk factors for sudden unexpected death in infancy and sudden infant death syndrome (SIDS). The clinical consequences (phenotype) are not known for the autonomic nervous system and serotonin transporter $(5-\mathrm{HTT})$ polymorphisms. Adapted from Hunt. ${ }^{70}$ 
ventilatory and arousal abnormalities and temperature or metabolic regulation deficits. Cardiorespiratory control deficits could be related to 5-HTT polymorphisms, for example, or to polymorphisms in genes pertinent to the development of the autonomic nervous system. Affected infants could be at increased risk of sleep-related hypoxemia and hence more susceptible to adverse effects associated with unsafe sleeping position or bedding. Infants at increased risk of sleep-related hypoxemia and secondary acidosis could also be at increased risk of fatal arrhythmias in the presence of a cardiac ion channelopathy. ${ }^{82}$

Recent febrile illness, often related to upper respiratory tract infection (Box I), has been observed in 50\% or more of SIDS cases. Although not considered to be of primary etiologic significance, such otherwise benign infections could increase the risk of SIDS in infants with genetically determined impaired immune responses (Box 2). ${ }^{75}$ Interactions between upper respiratory tract infection or other minor illnesses and other factors such as prone sleeping position may also play a role in the pathogenesis of SIDS. Mast-cell degranulation has been reported in SIDS cases, a finding consistent with an anaphylactic reaction to a bacterial toxin. Some family members of SIDS infants have been found to have mast-cell hyperreleasability and degranulation, which suggests that this may be another genetic factor influencing fatal outcomes in the presence of otherwise minor infections in infants. ${ }^{77}$

The increased risk of SIDS associated with fetal and postnatal exposure to cigarette smoke may be related at least in part to genetic factors affecting brainstem autonomic control. ${ }^{6,77}$ Both animal and clinical studies have shown decreased ventilatory and arousal responsiveness to hypoxia following fetal nicotine exposure, and impaired autoresuscitation after apnea has been associated with postnatal nicotine exposure. ${ }^{83-86}$ Decreased brainstem immunoreactivity to selected protein kinase $\mathrm{C}$ and neuronal nitric oxide synthase isoforms has been observed in rats exposed to cigarette smoke prenatally, another potential cause of impaired hypoxic responsiveness. ${ }^{87}$ Smoking increases susceptibility to viral and bacterial infections and increases bacterial binding after passive coating of mucosal surfaces with smoke components, implicating interactions between smoking, cardiorespiratory control and immune status. ${ }^{88,89}$

\section{Infants at increased risk of SIDS}

Infants at increased risk of SIDS include those who have had an apparent life-threatening event, siblings of prior SIDS infants and infants born preterm. ${ }^{6,7}$

An apparent life-threatening event is defined as a sudden, unexpected change in an infant that is frightening to the caregiver but does not lead to sudden death or persistent collapse. Sudden colour change (cyanosis or occasionally marked pallor) is the most frequent observation, typically associated with initial unresponsiveness to external stimulation; apparent apnea is another frequent observation. A history of an unexplained apparent life-threatening event has been reported in $5 \%-9 \%$ of SIDS infants, but no definitive incidence rates are available. The risk of SIDS may be up to
3-5 times greater among infants with such a history. ${ }^{6} \mathrm{Al}-$ though most studies of apparent life-threatening events have not specified gestational age at birth, 30\% of infants with such a history in the Collaborative Home Infant Monitoring Evaluation (CHIME) study had a gestational age of less than 38 weeks at birth. ${ }^{90}$

The next-born siblings of first-born infants dying of a natural cause have been found to be at significantly increased risk of death during infancy from the same cause, including SIDS. ${ }^{70,91-93}$ The risk of recurrent infant death from the same cause as in the index sibling is increased to a similar degree among subsequent siblings for both explained causes and for SIDS (relative risks for recurrence $5^{-1} 3$ and $5-6$, respectively). The extent to which the risk of SIDS may be increased in subsequent siblings is controversial, primarily because of the absence of objective criteria for ruling out intentional suffocation and to limited prior understanding of the role of genetic risk factors. ${ }^{70,71}$ However, there are now substantial data in support of genetic risk factors for recurrent SIDS, and recent epidemiologic data confirm that second infant deaths in families are not rare and that at least $80 \%-90 \%$ are natural. ${ }^{94}$ Recurrent infant death from SIDS in subsequent siblings is 6 times more likely than from homicide.

Many studies have identified an inverse relation between the risk of SIDS and birth weight or gestational age. ${ }^{6}$ The postnatal age of preterm infants who died of SIDS was found to be $5-7$ weeks more, and the postmenstrual age $4-6$ weeks less, than that of term infants who died of SIDS. ${ }^{95}$ Compared with infants whose birth weight was $2500 \mathrm{~g}$ or more, those with a birth weight of 1000-I499 g and 1500-2499 g were about 4 and 3 times more likely, respectively, to die of SIDS. ${ }^{96}$

\section{Clinical strategies}

\section{Intervention}

No method currently exists to identify future SIDS cases at birth, and there is no proven intervention even if prospective identification were feasible. No assessment of cardiorespiratory pattern or other autonomic abnormality has sufficient sensitivity and specificity to be useful for screening. There is no evidence that home electronic surveillance using existing technology reduces the risk of SIDS..$^{39}$ Although a prolonged QT interval can be treated, neither the role of routine neonatal electrocardiographic screening nor the safety of treatment has been established, and parental screening is not helpful owing to the high frequency of spontaneous mutations causing long QT syndrome in infants and to the variable presence of prolonged QT intervals in adults with a relevant genotype. ${ }^{70,77}$

Even though it is not possible to identify future SIDS infants at birth, it is possible to identify infants at high risk of SIDS based on combinations of established risk factors such as low birth weight, exposure to tobacco smoke, single parent, low maternal education and intent to bottle feed. Identifying high-risk infants can be the basis for targeted enhanced educational interventions to maximize adherence to recommendations for reducing the risk of SIDS. 


\section{Reducing the risk of SIDS}

This goal is achievable, as evidenced by the dramatic decreases in SIDS rates associated with reductions in prone and side sleeping positions and other modifiable risk factors. The new American Academy of Pediatrics (AAP) guidelines to reduce the risk of SIDS in individual infants are appropriate for most infants. ${ }^{39}$ The main components are summarized in Box 3.

The recommendations of the Canadian Paediatric Society (CPS) are very similar, the main exception being pacifier use. ${ }^{64}$ The CPS recommends that the use of pacifiers not be routinely discouraged, rather than encouraged, at bedtime. It also recommends that pacifiers continue to be used in neonatal intensive care units for non-nutritive sucking and comfort in the preterm or sick infant.

Recommendations about bed sharing have been controversial. The CPS and AAP have similar recommendations about bed sharing and room sharing: infants should sleep in safety-approved cribs for the first year of life under all circumstances, and parents should be made aware that room sharing is associated with lower SIDS rates. ${ }^{69}$ The CPS also recommends that hospitals not permit mothers to sleep in the same bed as their newborn during the postpartum period, while still ensuring maternal-infant interaction for successful breast-feeding initiation.

Because the majority of these recommendations are based on findings from observational studies rather than on evidence from randomized clinical trials, the effects of the newer guidelines remain to be seen. However, we support the AAP recommendations, since they are based on sound data and absence of any evidence of potential harm and are therefore likely to be effective.

\section{Summary}

SIDS is a complex, multifactorial disorder for which continued research is needed to fully understand the relevant interactions between genetic and environmental risk factors that affect causation. In the meantime, epidemiologic evidence and interventions based on this research have helped to reduce the incidence of SIDS. Current challenges include wider dissemination of guidelines to all people who care for infants, dissemination of guidelines in culturally appropriate ways, and the surveillance of SIDS trends and other outcomes associated with the implementation of these guidelines.

Box 3: Main components of the American Academy of Pediatrics guidelines to reduce the risk of sudden infant death syndrome (SIDS)

- Term and preterm infants should be placed on their back to sleep. There are no adverse health outcomes from a supine sleeping position. Infants should not be placed on their side to sleep.

- Infants should sleep in their own crib or bassinet that conforms to the safety standards of the Consumer Product Safety Commission, preferably in the same room as their parents. Placing the crib or bassinet near the mother's bed will facilitate breast-feeding and contact. Infants should never be placed in a bed or on a sofa or chair with other children. They should not be brought into bed with parents who are excessively tired or are using substances that may impair their alertness.

- Infants should be placed on a firm mattress to sleep. Waterbeds, sofas, soft mattresses or other soft surfaces should not be used.

- Soft materials in the infant's sleep environment should be avoided, either over, under or near the infant. These include pillows, comforters, quilts, sheepskins, cushion-like bumper pads and stuffed toys. Because loose bedding may be hazardous, blankets, if used, should be tucked in around the crib mattress. Sleep clothing, such as a sleep sack, may be used in place of blankets.

- Avoid overheating and overbundling. The infant should be lightly clothed for sleep and the thermostat set at a comfortable temperature.

- Infants should have some time in the prone position while awake and be observed. Alternating the placement of the infant's head as well as his or her orientation in the crib can also minimize the risk of head flattening from supine sleeping (positional plagiocephaly).

- The use of devices advertised to maintain sleep position, to "protect" a bed-sharing infant or to reduce the risk of rebreathing stale air are not recommended.

- Home monitoring may be of value for selected infants who have extreme instability. However, there is no evidence that monitoring decreases the incidence of SIDS, and it is therefore not recommended for this purpose.

- Consider the use of a pacifier at bedtime and naptime. The pacifier should be used when placing the infant down for sleep but not be reinserted once it falls out (after the infant falls asleep). For breast-fed infants, delay the introduction of a pacifier until the infant is 1 month old, to ensure that breast-feeding is well established.

- Mothers should not smoke during pregnancy, and infants should not be exposed to secondhand smoke.

- The national Back to Sleep campaign should be expanded to emphasize the multiple characteristics of a safe sleeping environment and to focus on the groups who continue to be at increased risk of SIDS. Educational strategies should be tailored to each racial/ethnic group to enhance compliance. In addition, these educational messages should be targeted to secondary care providers, including day-care providers, grandparents, foster parents, babysitters and health care professionals working in neonatal intensive care units and nurseries. 
This article has been peer reviewed.

From the National Heart, Lung, and Blood Institute (Hunt), Bethesda, Md., and the Departments of Family Medicine and Public Health Sciences, University of Virginia (Hauck), Charlottesville, Va.

\section{Competing interests: None declared.}

Contributors: Both authors made a substantial contributions to conception and design, acquisition of data, and interpretation of data; contributed to writing drafts of the article and revising it critically for important intellectual content; and approved the final version to be published.

\section{REFERENCES}

I. Willinger M, James LS, Catz C. Defining the sudden infant death syndrome (SIDS): deliberations of an expert panel convened by the National Institute of Child Health and Human Development. Pediatr Pathol 1991;11:677-84.

2. Hauck FR. Changing epidemiology. In: Byard RW, Krous HF, editors. Sudden infant death syndrome. Problems, progress and possibilities. London (UK): Arnold; 2004. p. 3I-57.

3. Mathews TJ, Menacker F, MacDorman MF; US Centers for Disease Control and Prevention National Center for Health Statistics. Infant mortality statistics from the 2002 period: linked birth/infant death data set. Natl Vital Stat Rep 2004;53:I-29.

4. Malloy MH, MacDorman M. Changes in the classification of sudden unexpected infant deaths: United States, I992-200I. Pediatrics 2005;I15:1247-53.

5. Byard RW, Beal SM. Has changing diagnostic preference been responsible for the recent fall in incidence of sudden infant death syndrome in South Australia? J Paediatr Child Health 1995;31:197-9.

6. Thompson MW, Hunt CE. Control of breathing: development, apnea of prematurity, apparent life-threatening events, SIDS. In: MacDonald MG, Mullett MD, Seshia MMK, editors. Avery's neonatology: pathophysiology and management of the newborn. 6th ed. Philadelphia: Lippincott Williams \& Wilkins; 2005. p. 535-52.

7. Hunt CE, Hauck FR. Sudden infant syndrome. In: Behrman RE, Kliegman RM, Jenson HB, editors. Nelson textbook of pediatrics. I7th ed. Philadelphia: Elsevier; 2004. p. I380-5.

8. Jones KL, Krous HF, Nadeau J, et al. Vascular endothelial growth factor in the cerebrospinal fluid of infants who died of sudden infant death syndrome: evidence for antecedent hypoxia. Pediatrics 2003;III:358-63.

9. Lavezzi AM, Ottaviani G, Mauri M, et al. Hypoplasia of the arcuate nucleus and maternal smoking during pregnancy in sudden unexplained perinatal and infant death. Neuropathology 2004;24:284-9.

Io. Mezei G, Kheifets L. Selection bias and its implications for case-control studies: case study of magnetic field exposure and childhood leukemia. Int J Epidemiol 2005;35:397-406

II. Daltveit AK, Oyen N, Skjaerven R, et al. The epidemic of SIDS in Norway 1967-93 changing effects of risk factors. Arch Dis Child i997;77:23-7.

I2. Blair PS, Sidebotham P, Berry PJ, et al. Major epidemiological changes in sudden infant death syndrome: a 20-year population-based study in the UK. Lancet 2006; 367:314-9.

I3. Kerbl R, Zotter H, Einspieler C, et al. Classification of sudden infant death (SID) cases in a multidisciplinary setting. Ten years experience in Styria (Austria). Wien Klin Wochenschr 2003;115:887-93.

I4. Dwyer T, Ponsonby AL, Newman NM, et al. Prospective cohort study of prone sleeping position and sudden infant death syndrome. Lancet I99I;337:1244-7.

I5. Pickett KE, Luo Y LD. Widening social inequalities in risk for sudden infant death syndrome. Am J Public Health 2005;95:1976-8I.

I6. Alm B, Norvenius SG, Wennergren G, et al. Changes in the epidemiology of sudden infant death syndrome in Sweden 1973-1996. Arch Dis Child 2001;84:24-30.

17. Arnestad M, Andersen M, Vege A, et al. Changes in the epidemiological pattern of sudden infant death syndrome in southeast Norway, I984-I998: implications for future prevention and research. Arch Dis Child 2001;85:108-15.

I8. Mitchell EA. The changing epidemiology of SIDS following the national risk reduction campaigns. Pediatr Pulmonol Suppl I997; 6:II7-9.

I9. Douglas AS, Allan TM, Helms PJ. Seasonality and the sudden infant death syndrome during I987-9 and I99I-3 in Australia and Britain. BMJ I996;3I2:I38I-3.

20. Brooke H, Gibson A, Tappin D, et al. Case-control study of sudden infant death syndrome in Scotland, 1992-5. BMJ 1997;314:1516-20.

2I. Hoffman HJ, Hillman LS. Epidemiology of the sudden infant death syndrome: prenatal, neonatal, and postneonatal risk factors. Clin Perinatol 1992;19:717-37.

22. Vennemann MM, Findeisen M, Butterfass-Bahloul, et al. Modifiable risk factors for SIDS in Germany: results of GeSID. Acta Paediatr 2005;94:655-6o.

23. Hauck FR, Moore CM, Herman SM, et al. The contribution of prone sleeping position to the racial disparity in sudden infant death syndrome: the Chicago Infant Mortality Study. Pediatrics 2002;110:772-80.

24. Carpenter RG, Irgens LM, Blair PS, et al. Sudden unexplained infant death in 20 regions in Europe: case control study. Lancet 2004;363:I85-9I.

25. Mitchell EA, Milerad J. Smoking and sudden infant death syndrome. In: International consultation on environmental tobacco smoke (ETS) and child health. Geneva: World Health Organization; 1999. p. I05-29.

26. Schellscheidt J, Фyen N, Jorch G. Interactions between maternal smoking and other prenatal risk factors for sudden infant death syndrome (SIDS). Acta Paediatr I997; $86: 857-63$.

27. Golding J. Sudden infant death syndrome and parental smoking - a literature review. Paediatr Perinat Epidemiol I997;1r:67-77.

28. Anderson HR, Cook DG. Passive smoking and sudden infant death syndrome: review of the epidemiological evidence. Thorax I999;54:365-6.

29. Schoendorf KC, Kiely JL. Relationship of sudden infant death syndrome to maternal smoking during and after pregnancy. Pediatrics i992;90:905-8.

30. Klonoff-Cohen HS, Edelstein SL, Lefkowitz ES, et al. The effect of passive smoking and tobacco exposure through breast milk on sudden infant death syndrome. JAMA 1995;273:795-8.

3I. Blair PS, Fleming PJ, Bensley D, et al. Smoking and the sudden infant death syndrome: results from the $1993-5$ case-control inquiry into stillbirths and deaths in infancy. BMJ I996;313:195-8.

32. Hoffman HJ, Damus K, Hillman L, et al. Risk factors for SIDS: results of the National Institute of Child Health and Human Development SIDS Cooperative Epidemiological Study. Ann N Y Acad Sci 1988;533:13-30.

33. Ward SLD, Bautista D, Chan L, et al. Sudden infant death syndrome in infants of substance-abusing mothers. J Pediatr I990;117:876-8I

34. Chavez CJ, Ostrea EM, Stryker JC, et al. Sudden infant death syndrome among infants of drug-dependent mothers. JPediatr 1979;95:407-9.

35. Kandall SR, Gaines J, Habel L, et al. Relationship of maternal substance abuse to subsequent sudden infant death syndrome in offspring. J Pediatr 1993;123:120-6.

36. Iyasu S, Randall LL, Welty TK, et al. Risk factors for sudden infant death syndrome among Northern Plains Indians. JAMA 2002;288:2717-23.

37. L'Hoir MP, Engelberts AC, van Well GTHJ, et al. Case-control study of current validity of previously described risk factors for SIDS in the Netherlands. Arch Dis Child I998;79:386-93.

38. Burd L, Klug MG, Martsolf JT. Increased sibling mortality in children with fetal alcohol syndrome. Addict Biol 2004;9:179-86.

39. Task Force on Sudden Infant Death Syndrome. The changing concept of sudden infant death syndrome: diagnostic coding shifts, controversies regarding the sleeping environment, and new variables to consider in reducing risk. Pediatrics 2005;II6:1245-55.

40. Markestad T, Skadberg B, Hordvik E, et al. Sleeping position and sudden infant death syndrome (SIDS): effect of an intervention programme to avoid prone sleeping. Acta Paediatr 1995;84:375-8.

4I. Li DK, Petitti DB, Willinger M, et al. Infant sleeping position and the risk of sudden infant death syndrome in California, 1997-2000. Am J Epidemiol 2003;157:446-55.

42. Henderson-Smart DJ, Ponsonby AL, Murphy E. Reducing the risk of sudden infant death syndrome: a review of the scientific literature. J Paediatr Child Health I998; 34:213-9.

43. Ponsonby AL, Dwyer T, Couper D. Sleeping position, infant apnea, and cyanosis: a population-based study. Pediatrics I997;99(I):E3.

44. Hunt CE, Lesko SM, Vezina RM, et al. Infant sleep position and associated health outcomes. Arch Pediatr Adolesc Med 2003;157:469-74.

45. Mitchell EA. Scragg l, Clements M. Soft cot mattresses and the sudden infant death syndrome. NZ Med J I996;Io9:206-7.

46. Hauck FR, Herman SM, Donovan M, et al. Sleep environment and the risk of sudden infant death syndrome in an urban population: the Chicago Infant Mortality Study. Pediatrics 2003;III:I207-I4.

47. Fleming PJ, Blair PS, Bacon C, et al. Environment of infants during sleep and the risk of sudden infant death syndrome: results of $1993^{-95}$ study for confidential inquiry into stillbirths and deaths in infancy. BMJ I996;313:I9I-5.

48. Ponsonby AL, Dwyer T, Gibbons LE, et al. Factors potentiating the risk of sudden infant death syndrome associated with the prone position. N Engl J Med I993;329: $377-82$.

49. Williams SM, Taylor BJ, Mitchell EA. Sudden infant death syndrome: insulation from bedding and clothing and its effect modifiers. Int J Epidemiol I996;25:366-75.

50. Scheers-Masters JR, Schootman M, Thach BT. Heat stress and sudden infant death syndrome incidence: a United States population epidemiologic study. Pediatrics 2004;II3:e586-92.

5I. Blair PS, Fleming PJ, Smith IJ, et al. Babies sleeping with parents; case-control study of factors influencing the risk of the sudden infant death syndrome. $B M$ I999;3I9:I457-62.

52. Scragg R, Mitchell EA, Taylor BJ, et al. Bed sharing, smoking, and alcohol in the sudden infant death syndrome. New Zealand Cot Death Study Group. BMJ I993; 307:1312-8.

53. Tappin D, Ecob R, Brooke H. Bedsharing, room sharing, and sudden infant death syndrome in Scotland: a case-control study. J Pediatr 2005;I47:32-7.

54. McGarvey C, McDonnell M, Chong A, et al. Factors relating to the infant's last sleep environment in sudden infant death syndrome in the Republic of Ireland. Arch Dis Child 2003;88:1058-64.

55. Mosko S, Richard C, McKenna J, et al. Infant sleep architecture during bedsharing and possible implications for SIDS. Sleep I996;19:677-84.

56. Mosko S, Richard C, McKenna J. Maternal sleep and arousals during bedsharing with infants. Sleep 1997;20:142-50.

57. Mitchell EA, Thompson JMD. Co-sleeping increases the risk of SIDS, but sleeping in the parents' bedroom lowers it. In: Rognum TO, editor. Sudden infant death syndrome. New trends in the nineties. Oslo: Scandinavian University Press; 1995. p. 266-9.

58. Chen A, Rogan WJ. Breastfeeding and the risk of postneonatal death in the United States. Pediatrics 2004; I1 $3:$ e435-9.

59. Hauck FR, Omojokun OO, Siadaty MS. Do pacifiers reduce the risk of sudden infant death syndrome? A meta-analysis. Pediatrics 2005;II6:e7I6-23.

6o. Li DK, Willinger M, Petittti DB, et al. Use of a dummy (pacifier) during sleep and 
risk of sudden infant death syndrome (SIDS): population based case-control study. BMJ 2006;332:18-22. [Epub 2005 Dec 9.]

6r. Franco P, Scaillet S, Wermenbol V, et al. The influence of a pacifier on infants' arousals from sleep. J Pediatr 2000; $136: 775-9$.

62. Franco P, Chabanski S, Scaillet $S$, et al. Pacifier use modifies infant's cardiac autonomic controls during sleep. Early Hum Dev 2004;77:99-108.

63. Fleming P, Blair P, Pollard K, et al. Pacifier use and sudden infant death syndrome: results from the CESDI/SUDI case control study. Arch Dis Child I999;8I:II2-6.

64. Community Paediatrics Committee; Canadian Paediatric Society. Recommendations for the use of pacifiers. Paediatr Child Health 2003;8:515-9.

65. Mitchell EA, Taylor BJ, Ford RP, et al. Dummies and the sudden infant death syndrome. Arch Dis Child I993;68:50I-4.

66. L'Hoir MP, Engelberts AC, van Well GTJ, et al. Dummy use, thumb sucking, mouth breathing and cot death. Eur J Pediatr I999;158:896-90I.

67. Jorch H, Schleimer B. The optimal sleep environment for your child. A guide for parents and all who want to become parents [translated from German]. Bochum (Germany): Johanniter-Unfall-Hilfe; I 998.

68. Foundation for the Study and Prevention of Infant Mortality. Safe sleeping. Available www.wiegedood.nl/modules/content/index.php?section=4 (accessed 2006 May 2).

69. Community Paediatrics Committee CPS. Recommendations for safe sleeping environments for infants and children. Paediatr Child Health 2004;9:659-63.

70. Hunt C E. Gene-environment interactions: implications for sudden unexpected deaths in infancy. Arch Dis Child 2005;90:48-53.

7I. Opdal SH, Rognum TO. The sudden infant death syndrome gene: Does it exist? Pediatrics 2004;II4:e506-I2.

72. Tester DJ, Ackerman MJ. Sudden infant death syndrome: How significant are the cardiac channelopathies? Cardiovasc Res 2005;67:388-96.

73. Kinney HC, Randall LL, Sleeper LA, et al. Serotonergic brainstem abnormalities in Northern Plains Indians with the sudden infant death syndrome. J Neuropatho Exp Neurol 2003;62:II78-01.

74. Weese-Mayer DE, Berry-Kravis EM, Zhou L, et al. Sudden infant death syndrome: case-control frequency differences at genes pertinent to early autonomic nervous system embryologic development. Pediatr Res 2004;56:39I-6.

75. Blackwell C. Infection, inflammation and SIDS [editorial]. FEMS Immunol Med Microbiol 2004;42:I-I46

76. Korachi M, Pravica V, Barson AJ, et al. Interleukin ro genotype as a risk factor for sudden infant death syndrome: determination of IL-Io genotype from wax-embedded postmortem samples. FEMS Immunol Med Microbiol 2004;42:125-9.

77. Hunt CE. Sudden infant death syndrome and other causes of infant mortality: diagnosis, mechanisms and risk for recurrence in siblings. Am J Respir Crit Care Med 200I; I64:346-57

78. Kahn A, Groswasser J, Franco P, et al. Sudden infant deaths: stress, arousal and SIDS. Early Hum Dev 2003;75(Suppl):SI47-66.

79. Froen JF, Akre H, Stray-Pedersen B, et al. Adverse effects of nicotine and inter leukin-IB on autoresuscitation after apnea in piglets: implications for sudden infant death syndrome. Pediatrics 2000;105(4):E52:I-5. 8o. Franco P, Szliwowski H, Dramaix M, et al. Decreased autonomic responses to obstructive sleep events in future victims of sudden infant death syndrome. Pediat Res i999;46:33-9.

8I. Waters KA, Gonzalez A, Jean C, et al. Face-straight-down and face-near-straightdown positions in healthy, prone-sleeping infants. J Pediatr 1996;128:616-25

82. Plant LD, Bowers PN, Liu Q, et al. A common cardiac sodium channel variant associated with sudden infant death in African Americans, SCN5A Siro3Y. J Clin Invest 2006; $116: 430-5$

83. Hafstrom O, Milerad J, Sundell HW. Prenatal nicotine exposure blunts the cardiorespiratory response to hypoxia in lambs. Am J Respir Crit Care Med 2002;166:1544-9.

84. Hafstrom O, Milerad J, Sundell HW. Altered breathing pattern after prenatal nicotine exposure in the young lamb. Am J Respir Crit Care Med 2002;I66:92-7.

85. Ueda Y, Stick SM, Hall G, et al. Control of breathing in infants born to smoking mothers. J Pediatr I999;135 (2 Pt I):226-32.

86. Franco P, Groswasser J, Hassid S, et al. Prenatal exposure to cigarette smoking is associated with a decrease in arousal in infants. J Pediatr 1999;135:34-8.

87. Hasan SU, Simakajornboon N, MacKinnon Y, et al. Prenatal cigarette smoke exposure selectively alters protein kinase $\mathrm{C}$ and nitric oxide synthase expression within the neonatal rat brainstem. Neurosci Lett 2001;301:135-8.

88. McMartin KI, Platt MS, Hackman R, et al. Lung tissue concentrations of nicotine in sudden infant death syndrome (SIDS). J Pediatr 2002;140:205 -9.

89. Kadhim H, Kahn A, Sébire G. Distinct cytokine profile in SIDS brain: a common denominator in a multifactorial syndrome. Neurology 2003;6I:I256-9.

9o. Ramanathan R, Corwin MJ, Hunt CE, et al and the CHIME Study Group. Cardiorespiratory events recorded on home monitors: comparison of healthy infants with those at increased risk for SIDS. JAMA 200I; 285:2199-207.

9I. Leach CEA, Blair PS, Fleming PJ, et al; CESDI SUDI Research Group. Epidemiology of SIDS and explained sudden infant deaths. Pediatrics I999;104(4): 433.

92. Oyen N, Skjaerven R, Irgens LM. Population-based recurrence risk of sudden infant death syndrome compared with other infant and fetal deaths. Am J Epidemiol I996;I44:300-5

93. Guntheroth WG, Lohmann R, Spiers PS. Risk for sudden infant death syndrome in subsequent siblings. J Pediatr I990;116:520-4.

94. Carpenter RG, Waite A, Coombs RC, et al. Repeat sudden unexpected and unexplained infant deaths: Natural or unnatural? Lancet 2005;365:29-35.

95. Malloy MH, Hoffman HI. Prematurity, sudden infant death syndrome, and age of death. Pediatrics 1995;96:464-7I.

96. Malloy MH, Freeman DH. Birth weight- and gestational age-specific sudden infant death syndrome mortality: United States, I99I versus I995. Pediatrics 2000;105: I227-3I.

Correspondence to: Dr. Carl E. Hunt, National Heart, Lung, and Blood Institute, 3 I Center Dr., MSC 2480, Bethesda MD 208922480, USA; fax 30I 402-I05I; huntc@nhlbi.nih.gov
The complete picture on research.

PRACTICAL. RELEVANT. CMAJ IS NOW MORE COMPREHENSIVE THAN EVER.

CMAJ's reputation and wide Canadian and international reach make it THE place to publish leading Canadian research. CMAJ publishes important peer-reviewed research within weeks of submission and ranks fifth among international general medical journals by impact factor, a measure of the scientific importance of a journal.

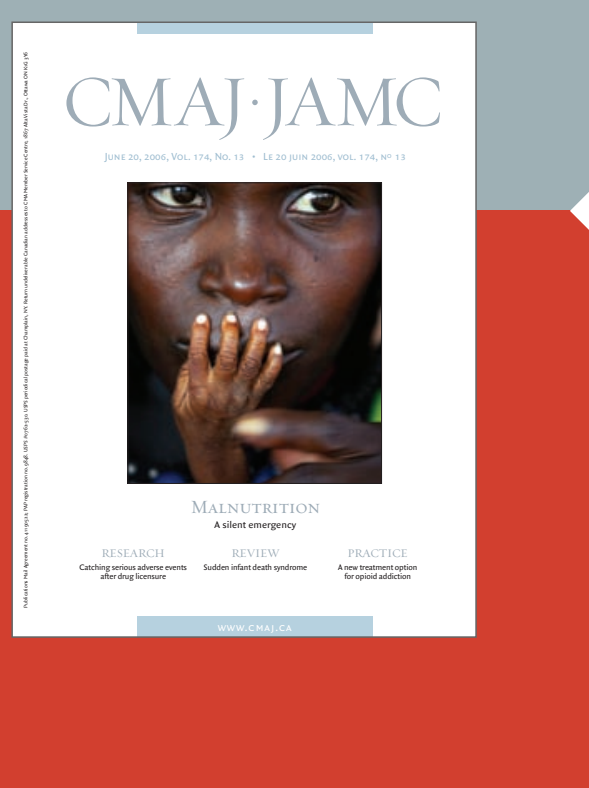

The essential read. ${ }^{\mathrm{TM}}$ 